\title{
APLICAÇÃO DE PREPARAÇÃO PECTINOLÍTICA FÚNGICA OBTIDA POR CULTIVO EM ESTADO SÓLIDO NA EXTRAÇÃO DE SUCO DE UVA
}

\author{
P. POLETTO, C. BORSOI, C. REGINATTO, M. ZENI, M.M. SILVEIRA \\ Universidade de Caxias do Sul, Instituto de Biotecnologia \\ Email: ppoletto@ucs.br
}

\begin{abstract}
RESUMO - Pectinases foram produzidas em meio sólido, em biorreator de tambor rotativo, por Aspergillus niger, extraídas em água e concentradas por ultrafiltração. A atividade enzimática em função da temperatura e $\mathrm{pH}$ de reação mostraram valores ótimos em $\mathrm{pH} 4,0$ e $60^{\circ} \mathrm{C}$. No ensaio de estabilidade frente à temperatura, as enzimas apresentaram atividades relativas de 76,1 e 19,5\% após 1 h de incubação a 50 e $60^{\circ} \mathrm{C}$, respectivamente. No tratamento enzimático de suco de uva, o desempenho da preparação experimental foi comparado ao de enzimas comerciais. Todas as preparações testadas mostraram efeito positivo semelhante na redução de sólidos insolúveis, viscosidade, turbidez e aumento do grau de clarificação do suco, com ganho significativo em relação à amostra sem adição de enzimas. $\mathrm{O}$ teor de polifenóis totais nos sucos tratados com as enzimas comerciais foi reduzido em torno de $20 \%$, enquanto a preparação experimental não apresentou diferença significativa em relação ao suco controle, revelando seu grande potencial de aplicação no processamento de sucos de frutas.
\end{abstract}

\section{INTRODUÇÃO}

O potencial biotecnológico das enzimas pectinolíticas microbianas tem atraído atenção em todo o mundo devido às suas muitas aplicações. As pectinases possuem grande destaque na indústria de alimentos, sendo usadas, principalmente, na maceração dos tecidos vegetais. Também são utilizadas em outros processamentos industriais, como na indústria têxtil, no processamento do café, na extração de óleos vegetais, no tratamento de águas residuárias contendo material pectínico, na extração e clarificação de sucos de frutas e na indústria de papel (Jayani et al. 2005; Gummadi \& Panda, 2003; Shanley et al. 1993).

As substâncias pécticas são responsáveis pela consistência, turbidez e aparência dos sucos de frutas, causando um considerável aumento na viscosidade, o que dificulta a operação de filtração e, consequentemente, a concentração do produto (Echavarría et al. 2011; Alkorta et al. 1997). Para minimizar esse problema, as enzimas pectinolíticas podem ser usadas em diferentes estágios da produção de sucos. Na etapa de maceração, são capazes de aumentar o rendimento a partir da polpa e melhorar a qualidade do produto final. $\mathrm{Na}$ etapa de despectinizaçao, ocorre aumento da clarificação, redução de viscosidade e turbidez, promovendo maior estabilidade durante a estocagem (Landbo \& Meyer, 2004; Grassin \& Fauquemberg, 1996). No trabalho de Díaz et al. (2013), o tratamento de suco de laranja com extrato pectinolítico produzido por cultivo em estado sólido promoveu redução significativa de turbidez quando comparada a uma preparação comercial. Rinaldi et al. (2013) mostraram 
que o tratamento com enzimas pectinolíticas resultou em aumento de duas vezes na extração de polifenóis e redução de $40 \%$ na turbidez. Sandri et al. (2011) constataram que o tratamento dos sucos de maçã e mirtilo com pectinases produzidas por A. niger promoveu aumento na clarificação, sem afetar o teor de compostos fenólicos e a capacidade antioxidante dos sucos. No mesmo trabalho, ainda foi mostrado que o extrato pectinolítico obtido por cultivo em estado sólido apresentou resultados superiores ao extrato produzido em cultivo submerso por uma linhagem de A. oryzae. Nur'Aliaa et al. (2011) demonstraram que o uso de pectinases favorece as características físico-químicas do suco de pitaia (fruto de cactos), aumentando o conteúdo de proteínas e polifenóis totais. Segundo Sandri et al. (2013), um fator importante, que deve ser levado em consideração, no desempenho das enzimas são as características do substrato, já que a mesma variedade da fruta pode apresentar diferentes valores de acidez, $\mathrm{pH}$ e conteúdo de inibidores, afetando, assim, os resultados.

Neste contexto, o presente trabalho teve como objetivo caracterizar um extrato pectinolítico produzido por uma nova linhagem de $A$. niger, em cultivo em estado sólido, com respeito às faixas ideais de $\mathrm{pH}$ e temperatura com vistas à sua aplicação na obtenção de suco de uva.

\section{MATERIAIS E MÉTODOS}

\subsection{Produção de pectinases por $A$. niger em cultivo em meio sólido}

O meio usado no cultivo consistiu de farelo de trigo, pectina cítrica, glicose e sais nutrientes. Após autoclavado a 1atm por 15 minutos, o meio foi inoculado com suspensão de esporos de A.niger LB-02-SF ( $10^{7}$ conídios por grama de meio úmido), sendo a umidade inicial ajustada em $53 \%$.

Os cultivos foram realizados em biorreator de tambor rotativo em escala de laboratório (Polidoro et al. 2009), com massa de substrato úmido de $1100 \mathrm{~g}$, correspondendo a uma ocupação média de $30 \%$ do volume útil disponível. A frequência de agitação empregada foi de $1 \mathrm{rpm}$, por 5 minutos a cada $2 \mathrm{~h}$. $\mathrm{O}$ reator foi aerado com ar úmido, à vazão de $0,36 \mathrm{~L}$ ar. $\mathrm{Kg}^{-1}$ meio.min ${ }^{-1}$, a $30^{\circ} \mathrm{C}$, nas primeiras $24 \mathrm{~h}$ e posteriormente a $25^{\circ} \mathrm{C}$ até $96 \mathrm{~h}$. Ao final do cultivo, as enzimas foram extraídas do meio sólido em água $\mathrm{pH} 4,0$, em agitador recíproco (200 rpm, $60 \mathrm{~min}, 20^{\circ} \mathrm{C}$ ), e concentradas por ultrafiltração com membrana polimérica com ponto molecular de corte de $10 \mathrm{kDa}$ (MILLIPORE, EUA).

\subsection{Atividade enzimática em função da temperatura e pH}

As condições de $\mathrm{pH}$ e temperatura em que ocorre a atividade máxima foram medidos para o extrato enzimático experimental. Os valores de $\mathrm{pH}$ testados variaram de 2 a 7 e os valores de temperatura de 20 a $80^{\circ} \mathrm{C}$.

A termoestabilidade do extrato pectinolítico a diferentes temperaturas (30 a $50^{\circ} \mathrm{C}$ ) também foi avaliada. Os valores de atividade residual medidos em diferentes tempos foram plotados e a constante de inativação da enzima foi calculada pela linearização da equação de Arrhenius (1) : 


$$
\ln \left(A_{t} / A_{o}\right)=-\mathrm{kt}
$$

onde $A_{t}$ é atividade de pectinase no tempo $t\left(\mathrm{Uml}^{-1}\right)$ e $\mathrm{A}_{\mathrm{o}}$ é a atividade de pectinase no início do ensaio $\left(\mathrm{Uml}^{-1}\right), \mathrm{k}$ é a constante de inativação e t é o tempo em minutos. Com o valor de $\mathrm{k}$, o tempo de meia vida $\mathrm{t}_{1 / 2}$ em minutos pode ser calculado (2):

$$
t_{1 / 2}=\ln (2) / k
$$

\subsection{Tratamento enzimático de suco de uva - Maceração}

Uvas da variedade bordô foram higienizadas, pesadas e acondicionadas em embalagens plásticas onde foram levemente esmagadas para facilitar a ação das enzimas. Duas preparações comercias (Novozym 33095 e Pectinex Ultra SP-L) e o extrato enzimático (EE) produzido neste trabalho foram utilizados na etapa de maceração realizada por 45 minutos a $45^{\circ} \mathrm{C}$. O volume de soluções de enzimas adicionado foi calculado com base na atividade de cada preparação, sendo utilizadas 25 unidades enzimáticas por $100 \mathrm{~g}$ de fruta. Os tratamentos enzimáticos e o ensaio controle foram realizados em duplicata. Os sucos foram extraídos por prensagem através de filtros de poliéster, aquecidos a $100^{\circ} \mathrm{C}$ por 1 minuto para interromper a ação das enzimas e, em seguida, centrifugados.

\subsection{Métodos Analíticos}

A atividade enzimática de pectinases totais foi determinada pela medida da redução da viscosidade de solução de pectina cítrica (CP KELCO S.A., Brasil) 0,5\% (m/v), em tampão acetato $0,05 \mathrm{M} \mathrm{pH} 4$. Uma unidade de pectinases totais é definida como a quantidade de enzima que causa a redução de $50 \%$ da viscosidade da solução e expressa em U/mL.

$\mathrm{O}$ pH do suco foi medido em pHmetro. O grau de clarificação foi determinado com base na intensidade de cor medida por absorbâncias a 420, 520 e $620 \mathrm{~nm}$ (Sandri et al., 2013). A viscosidade foi medida em viscosímetro a $30{ }^{\circ} \mathrm{C}$ e a turbidez foi determinada em turbidímetro. O teor de polifenóis totais foi determinado por quantificação espectrofotométrica, pelo procedimento Folin-Ciocalteau de Singleton \& Rossi (1965), com modificações.

\section{RESULTADOS E DISCUSSÃO}

\subsection{Caracterização das condições ótimas de reação e estabilidade térmica do extrato enzimático}

As enzimas apresentam faixas características de temperatura e $\mathrm{pH}$ em que ocorrem as suas máximas atividades. No processamento de sucos de frutas, o processo se limita à variação de temperatura, já que o $\mathrm{pH}$ é naturalmente constante e não pode ser variado. Portanto, o extrato enzimático fúngico obtido por cultivo em estado sólido foi caracterizado quanto ao $\mathrm{pH}$ e temperatura de reação em que ocorre a maior atividade (Fig 1). A atividade em função do $\mathrm{pH}$ foi máxima no valor de 4,0. Para os valores de $\mathrm{pH}$ 2,0 e 3,0, a atividade relativa foi de $80 \%$, enquanto que para $\mathrm{pH}$ acima de 5,0 a atividade reduziu para menos de 
$40 \%$ da condição padrão. Esse resultado indica a possibilidade de aplicação do extrato, já que a maioria dos sucos de frutas apresenta $\mathrm{pH}$ menor que 4.

Entre as temperaturas testadas $\left(20\right.$ a $\left.80^{\circ} \mathrm{C}\right)$, houve um aumento da atividade relativa com o incremento até $60^{\circ} \mathrm{C}$. Temperaturas entre 40 e $60^{\circ} \mathrm{C}$ são comuns no processamento de sucos de frutas, nas etapas de maceração e clarificação. No caso de aplicação do extrato enzimático, o perfil de atividade com o aumento de temperatura auxilia na identificação da faixa de temperatura em que a enzima sofre desnaturação.
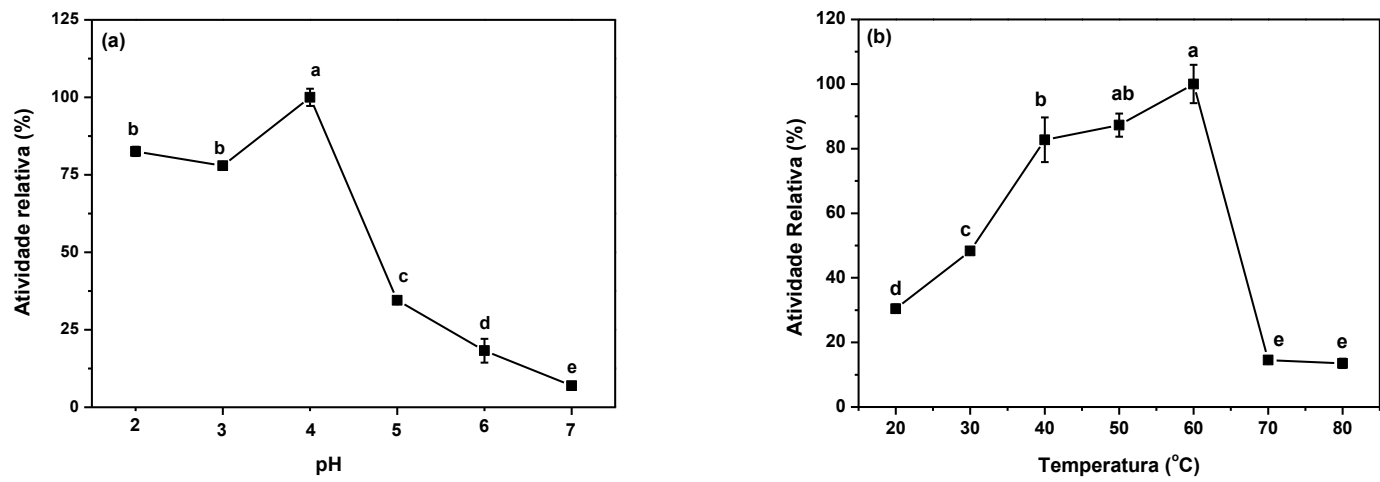

Figura 1 - Atividade de pectinases totais em função do $\mathrm{pH}\left(30^{\circ} \mathrm{C}\right)(\mathrm{a})$; e temperatura $(\mathrm{pH} 4)$.

Letras diferentes $(\mathrm{a}-\mathrm{e})$ indicam diferença estatisticamente diferente $(\mathrm{p}<0,05)$.

Além da temperatura de reação, há a necessidade de caracterizar-se a termoestabilidade das enzimas. Como mostra a Tabela 1, o extrato pectinolítico mostrou-se estável nas temperaturas de 20 e $30{ }^{\circ} \mathrm{C}$. Com o aumento da temperatura, ocorreu redução gradual da atividade relativa, sendo que a $60{ }^{\circ} \mathrm{C}$, apenas $17 \%$ da atividade é mantida após 120 min de incubação do extrato. Esses resultados são similares aos de Silva et al. (2007) em que o extrato pectinolítico fúngico produzido em CES apresentou em torno de $60 \%$ e $18 \%$ da atividade ao final de 60 minutos a $45^{\circ} \mathrm{C}$ e $60^{\circ} \mathrm{C}$, respectivamente. Com os dados de $\mathrm{k} \mathrm{e}_{1 / 2}$, foi possível estimar a termoestabilidade da enzima em diferentes temperaturas. As temperaturas de 40 e $50{ }^{\circ} \mathrm{C}$, geralmente utilizadas no processamento de sucos de frutas, apresentaram $\mathrm{t}_{1 / 2}$ suficientes para a realização da etapa de clarificação, por exemplo. Para enzimas comerciais, Ortega et al. (2004) relatam $\mathrm{t}_{1 / 2}$ de 200 a $30 \mathrm{~min}$ na temperatura de $50^{\circ} \mathrm{C}$. Esses dados variam de acordo com as propriedades químicas e bioquímicas que caracterizam as enzimas, as quais são definidas em função do microrganismo produtor e condições de cultivo empregadas na produção (Jayane et al., 2005).

Tabela 1 - Efeito da temperatura na atividade enzimática, constante de desnaturação e tempo de meia vida. *Atividade medida após $1 \mathrm{~h}$.

\begin{tabular}{lcccc}
\hline Temperatura $\left({ }^{\circ} \mathrm{C}\right)$ & $\begin{array}{c}\text { Atividade } \\
\text { relativa }(\%)^{*}\end{array}$ & $\mathrm{k}\left(\mathrm{min}^{-1}\right)$ & $\mathrm{R}^{2}$ & $\mathrm{t}_{1 / 2}(\min )$ \\
\hline 30 & 98,8 & 0,00085 & 0,944 & 815,5 \\
40 & 84,8 & 0,0097 & 0,948 & 233,4 \\
50 & 71,6 & 0,00645 & 0,938 & 97,2 \\
60 & 19,5 & - & - & - \\
\hline
\end{tabular}




\subsection{Efeito do Tratamento Enzimático de Sucos de Uva - Maceração}

O tratamento enzimático no processamento de sucos é uma prática comum. No processamento de sucos de uva, na etapa de maceração, por exemplo, as uvas já esmagadas são aquecidas e a preparação enzimática é adicionada (Filho, 2010). As enzimas comerciais Pectinex Ultra SP-L® e Novozym 33095 (Novozymes) foram usadas como parâmetro de comparação para o extrato enzimático experimental (EE) na maceração de suco de uva. $\mathrm{Na}$ Tabela 2, encontram-se informações sobre as enzimas comercias e o extrato EE. A dosagem de cada enzima foi estipulada com base nos valores de atividade medidos, sendo adicionadas 25 unidades de enzima para cada 100 g de uva.

Tabela 2 - Preparações enzimáticas empregadas neste trabalho na extração de suco de uva.

\begin{tabular}{|c|c|c|c|c|c|}
\hline Enzima & $\begin{array}{l}\text { TPA }^{a} \\
(\mathrm{U} / \mathrm{mL})\end{array}$ & $\begin{array}{l}\text { Linhagem } \\
\text { produtora }\end{array}$ & $\begin{array}{c}\mathrm{pH} \\
\text { ótimo }\end{array}$ & $\begin{array}{c}\text { Temperatura } \\
\text { ótima }\left({ }^{\circ} \mathrm{C}\right)\end{array}$ & $\begin{array}{c}\text { Dosagem } \\
(\mathrm{ml} / \text { ton })\end{array}$ \\
\hline $\begin{array}{l}\text { Novozym } \\
33095^{b}\end{array}$ & 2500 & $\begin{array}{c}\text { A. aculeaus } \\
\text { A. niger }\end{array}$ & $3,5-4,2$ & 60 & $50-250$ \\
\hline $\begin{array}{l}\text { Pectinex } \\
\text { Ultra SP-L }\end{array}$ & 1640 & A. aculeaus & $3,5-4,2$ & 60 & $100-200$ \\
\hline $\mathrm{EE}$ & 340 & A. niger & $4^{\mathrm{a}}$ & $50-60^{a}$ & nd \\
\hline
\end{tabular}

Enzimas pectinolíticas produzidas por A. niger em cultivo em estado sólido têm sido empregadas no processamento de sucos de frutas, mostrando resultados comparáveis às enzimas comerciais (Díaz et al., 2011, Sandri et al., 2013). O extrato obtido neste trabalho, também produzido por $A$. niger, apresentou resultados estatisticamente iguais aos apresentados pelas enzimas comerciais, como mostra a Tabela 3. As enzimas apresentaram efeito positivo na redução de sólidos insolúveis, redução de viscosidade, turbidez e aumento da clarificação variando significativamente da amostra controle (sem adição de enzimas).

Tabela 3 - Parâmetros analisados na etapa de maceração do processamento de suco de uva.

\begin{tabular}{lccccccc}
\hline Enzima & $\mathrm{pH}$ & $\begin{array}{c}\text { Rendimento } \\
(\%)\end{array}$ & $\begin{array}{c}\text { Sólidos } \\
\text { Insolúveis } \\
(\%)\end{array}$ & $\begin{array}{c}\text { Viscosidade } \\
(\mathrm{cp})\end{array}$ & $\begin{array}{c}\text { Clarificação } \\
(\mathrm{abs})\end{array}$ & $\begin{array}{c}\text { Turbidez } \\
(\mathrm{NTU})\end{array}$ & $\begin{array}{c}\text { Polifenóis } \\
\text { Totais } \\
(\text { EAG/100mL })\end{array}$ \\
\hline Controle & $3,24^{\mathrm{a}}$ & $75,5 \pm 1,9^{\mathrm{b}}$ & $3,7 \pm 0,3^{\mathrm{a}}$ & $3,43 \pm 0,10^{\mathrm{a}}$ & $0,403 \pm 0,05^{\mathrm{a}}$ & $139,3 \pm 23^{\mathrm{a}}$ & $8425 \pm 613^{\mathrm{a}}$ \\
${ }^{\mathrm{A}} \mathrm{N} 33095$ & $3,23^{\mathrm{a}}$ & $79,1 \pm 1,3^{\mathrm{a}}$ & $2,3 \pm 0,1^{\mathrm{b}}$ & $1,84 \pm 0,14^{\mathrm{b}}$ & $0,209 \pm 0^{\mathrm{b}}$ & $48,1 \pm 2,1^{\mathrm{bc}}$ & $6495 \pm 88^{\mathrm{b}}$ \\
${ }^{\mathrm{B}}$ Pectinex & $3,27^{\mathrm{a}}$ & $77,3 \pm 0,3^{\mathrm{b}}$ & $2,3 \pm 0^{\mathrm{b}}$ & $1,89 \pm 0,07^{\mathrm{b}}$ & $0,323 \pm 0,02^{\mathrm{ab}}$ & $43,1 \pm 4,6^{\mathrm{c}}$ & $6851 \pm 310^{\mathrm{b}}$ \\
$\mathrm{F}^{\mathrm{F} 0}$ & $3,25^{\mathrm{a}}$ & $74,2 \pm 0,3^{\mathrm{b}}$ & $2,5 \pm 0,2^{\mathrm{b}}$ & $1,99 \pm 0,01^{\mathrm{b}}$ & $0,290 \pm 0,02^{\mathrm{ab}}$ & $63,1 \pm 3,4^{\mathrm{b}}$ & $9271 \pm 358^{\mathrm{a}}$
\end{tabular}

A - Novozym 33095; B - Pectinex Ultra SP-L. Letras diferentes (a-c) indicam diferença significativa em nível de 5\% $(\mathrm{p}<0,05)$.

O nível de sólidos insolúveis pode variar de 4 a $8 \%$ dependendo da intensidade dos tratamentos de separação e prensagem realizados (Filho, 2010). Segundo os Padrões de 
Identidade e Qualidade fixados para o suco de uva, esse limite é de no máximo 5\% (v/v) (Brasil, 2000). No caso, o método utilizado na extração do suco, gerou presença de sólidos insolúveis em torno de $2,5 \%$ em todos os tratamentos enzimáticos, o que estaria de acordo com a legislação.

Redução de viscosidade em torno de $45 \%$ foi obtida em relação ao suco controle para todas as preparações enzimáticas testadas. A redução da viscosidade obtida pelo tratamento enzimático possibilita maior eficiência em etapas como a filtração por membranas, por exemplo, já que reduz a formação de fouling, evitando quedas acentuadas do fluxo de permeado (Machado et al,. 2012, Maktouf et al., 2014).

Os valores de absorbância medidos para avaliar a clarificação indicam que o tratamento enzimático apresenta um papel importante na hidrólise de compostos pectinolíticos e celulolíticos contribuindo para o aumento da clarificação do suco em relação ao suco controle, o que, nesse caso, foram de 48, 20 e 28\% para as preparações Novozymes 33095, Pectinex Ultra SP-L e EE, respectivamente. Já os valores de turbidez foram reduzidos em mais de $50 \%$. Segundo Pinelo et al., (2010), a turbidez é reduzida devido ao efeito das pectinases na degradação de substâncias pécticas, que são reduzidas em pequenas frações que se aglomeram e precipitam.

As enzimas pectinolíticas degradam os polissacarídeos presentes na parede celular da casca da uva liberando cor e compostos fenólicos (Romero-Cascales et al., 2012). Porém, o teor de polifenóis totais encontrado nos sucos tratados com as enzimas comerciais foi reduzido em torno de $20 \%$ quando comparado ao suco controle. Essa redução pode estar relacionada com a formação de complexos proteína-polifenóis (Rinaldi et al., 2013) e a uma capacidade enzimática secundária (Zielinski et al., 2014). Já a preparação EE, produzida neste trabalho, não apresentou diferença significativa no teor de polifenóis em relação ao suco controle. Sandri et al., (2013) obtiveram resultados similares utilizando extrato pectinolítico produzido por A. niger, mantendo o teor de polifenóis superior ao obtido pela enzima comercial Pectinex Be Color na clarificação de suco de mirtilo. O resultado obtido com o EE para o teor de polifenóis totais é muito positivo, já que essas substâncias já demonstraram efeitos de proteção à saúde humana contra diversas doenças (Oszmiański et al., 2011).

\section{CONCLUSÕES}

O extrato enzimático produzido por $A$. niger em cultivo em estado sólido, ainda que em escala laboratorial, apresentou desempenho similar ao de preparações enzimáticas comerciais na preparação de suco de uva. Esse resultado reafirma o potencial de desenvolvimento de um produto alternativo aos atualmente disponíveis no mercado que, na sua grande maioria, são importados pela indústria brasileira.

\section{REFERÊNCIAS}

ALKORTA, I.; GARBISU, C.; LLAMA, M.J.; SERRA, J.L. (1997). Industrial applications of pectic enzymes: review. Process Biochem., 33:21-28. 
BRASIL, Ministério da Agricultura e Abastecimento. Regulamento técnico para fixação dos padrões de identidade e qualidade para suco de uva. Instrução Normativa $\mathrm{N}^{\mathrm{o}} 01$, de 7 Janeiro de 2000.

DÍAZ, A.B.; BOLÍVAR, J.; ORY, I.; CARO, I.; BLANDINO, A. (2011).Applicability of enzymatic extracts obtained by solid state fermentation on grape pomace and orange peels mixtures in must clarification. LWT-Food Sci. Technol., 44:840-846.

DÍAZ, AB.; ALVARADO, O.; ORY, I.; CARO, I.; BLANDINO, A. Valorization of grape pomace and Orange peels: Improved production of hydrolytic enzymes for the clarification of orange juice. Food Bioprod. Process, v. 91, p. 580-586, 2013.

ECHAVARRÍA, A.P.; TORRAS, C.; PAGÁN, J.; IBARZ, A. (2011). Fruit juice processing and membrane technology application. Food Eng. Reviews, 3:136-158.

FILHO, W. G.V. Bebidas não alcoólicas: ciência e tecnologia. São Paulo: E. Blücher, 2010. $385 \mathrm{p}$.

GRASSIN, C.; FAUQUEMBERGUE, P. (1996). Application of pectinases in beverages. Progress in Biotechonol., 14:453-462.

GUMMADI, S.N.; PANDA, T. (2003). Purification and biochemical properties of microbial pectinases - a review. Process Biochem., 38:987-996.

JAYANI, R.S.; SAXENA, S.; GUPTA, R. (2005). Microbial pectinolytic enzymes: a review. Process Biochem., 40:2931-2944.

LANDBO, A-K.; MEYER, A.S. Effects of differents enzymatic maceration treatments on enhancement of anthocyanins and other phenolics in black currant juice. Innov. Food Sci. Emerg. Technol., v. 5, p. 503-513, 2004.

MACHADO, R.M.D.; HANEDA, R.N.; TREVISAN, B.P.; FONTES, S.R. (2012). Effect of enzymatic treatment on the cross-flow microfiltration of açaí pulp: Analysis of the fouling and recovery of phytochemical. J. Food Eng., 113: 442-452.

MAKTOUF, S.; NEIFAR, M.; DRIRA, S.J.; BAKLOUTI, S.; FENDRI, M.; CHÂABONI, S.E. Lemon juice clarification using fungal pectinolytic enzymes coupled to membrane ultrafiltration. Food Bioprod. Process., v. 92, p. 14-19, 2014.

NUR'ALIAA, A.R.; SITIMAZLINA, M.K.; TAIP, F.S. (2011). Effects of commercial pectinases application selected properties of red pitaya juice. J. Food Process Eng., 34: 1523-1534.

ORTEGA, N.; DIEGO, S; PEREZ-MATEOS, M.; BUSTO, M.D. Kinetic properties and thermal behavior of polygalacturonase used in fruit juice clarification. Food Chem. v. 88, p. 209-217, 2004. 
OSZMIAŃSKI, J.; WOJDYŁO A.; KOLNIAK, J. Effect of pectinase treatment on extraction of antioxidant phenols from pomace, for the production of puree-enriched cloudy apple juices. Food Chem., v. 127, p. 623-631, 2011.

PINELO, M.; ZEUNER, B.; MEYER, A.S. Juice clarification by protease and pectinases treatments indicates new roles of pectin and protein in cherry juice turbidity. Food Bioprod. Process., v. 88, p. 259-265, 2010.

POLIDORO, T.A.; SILVEIRA, M. M.; GELAIN, L. (2009). Dispositivo de tambor rotativo. Instituto Nacional de Propriedade Industrial - INPI, MU8901075-2.

RINALDI, M.; CALIGIANI, A; BORGESE, R.; PALLA, G.; BARABANTI, D.; MASSINI, $\mathrm{R}$. The effect of fruit processing and enzymatic treatments on pomegranate juice composition, antioxidant activity and polyphenols content. LWT- Food Sci. Technol., $53: 355-359$

ROMERO-CASCALES, I.; ROS-GARCÍA, J.M.; LÓPEZ-ROCA, J.M.; GÓMEZ-PLAZA, E. The effect of a commercial pectolytic enzyme on grape skin cell wall degradation and colour evolution during the maceration process. Food Chem., v. 130, p. 626-631, 2012.

SANDRI, I.G., LORENZONI, C.M.T., FONTANA, R.C., SILVEIRA, M.M. (2013). Use of pectinases produced by a new strain of Aspergillus niger for the enzymatic treatment of apple and blueberry juice, LWT-Food Sci. Technol., 51: 459-475.

SHANLEY, N.A.; VAN DEN BROEK, L.A.M.; VORAGEN, A.G.J.; COUGHLAN, M.P. (1993).Isolation and characterization of an endopolygalacturonase from Phanerochaete chrysosporium. J. Biotechnol., 28:179-197.

SILVA, D. MARTINS, E.S., LEITE, R.S.R., SILVA, R. FERREIRA, V., GOMES, E. (2007). Purification and characterization of an exo-polygalacturonase produced by Penicillium viridicatun RFC3 in solid- state fermentation. Process Biochem., 42: 1237-1243.

SINGLETON, V.L.; ROSSI, J.A.Jr. Colorimetric of total phenolics with phosphomolybdicphosphotungstic acid reagents. Amer. J. Enol. Viticult., v. 16, p. 144-158, 1965.

ZIELINSKI, A.A.F.; ALBERTI, A.; BRAGA, C.M.; SILVA, K.M.; CANTERI, M.H.G.; MAFRA, L.I.; GRANATO, D.; NOGUEIRA, A.; WOSIACKI, G. Effect of mash maceration and ripening stage of apples on phenolic compounds and antioxidant power of cloudy juices: A study using chemometrics. LWT - Food Sci. Technol., v. 57, p. 223229, 2014. 